\title{
Water quality effects of simulated conservation practice scenarios in the Little River Experimental watershed
}

\author{
J. Cho, G. Vellidis, D.D. Bosch, R. Lowrance, and T. Strickland
}

\begin{abstract}
The goal of this study was to evaluate the water quality effects of alternative conservation practice scenarios using the SWAT (Soil and Water Assessment Tool) model in the Little River Experimental watershed, a representative coastal plain watershed located in southern Georgia. We simulated the water quality effect of two suites of upland conservation practices (CPs) - one targeting erosion and the other targeting nutrients. We also simulated the impact of riparian forest buffers. Finally, we evaluated three different management scenarios for implementing the upland CPs: using a random approach, using subwatershed stream order as a prioritization criterion, and using subwatershed nonpoint source pollutant load as a prioritization criterion. The study showed that using subwatershed nonpoint source pollutant load as a prioritization criterion resulted in the most rapid water quality improvements. This improvement in water quality was nonlinear, while the other implementation schemes yield linear returns. Full implementation of the suite of CPs targeting erosion resulted in the greatest reductions of sediment (54.7\%) and total phosphorus (55.9\%) loads from upland crop areas. Full implementation of the suite of CPs targeting nutrient reduction resulted in the greatest total nitrogen load reduction (10.3\%). Overall, an intact riparian forest buffer offered the most comprehensive reduction of nonpoint source pollutant loads $-20.5 \%$ for sediment $19.5 \%$ for total phosphorus, and $7.0 \%$ for total nitrogen. Simulation results indicate that at the current time, the single greatest contributor to nonpoint source pollutant reduction in the Little River Experimental watershed may be the current level of riparian forest cover.
\end{abstract}

Key words: alternative scenarios-buffer-conservation practices-nutrients-riparian forest — sediment - Soil and Water Assessment Tool (SWAT) — water quality

\begin{abstract}
The Conservation Effects Assessment Project (CEAP) was initiated by the USDA to quantify the environmental benefits of conservation practices (CPs) applied to agricultural land over the past 40 years. Most of these CPs were implemented with technical and/or financial assistance from the USDA Natural Resources Conservation Service (NRCS) and its precursor, the USDA Soil Conservation Service. Watershed Assessment Studies, one of the CEAP components, contains three categories of watershed assessments: USDA Agricultural Research Service (ARS) benchmark watersheds, USDA NRCS special emphasis watersheds, and USDA Cooperative State Research, Education, and Extension Service competitive grants program watersheds (Richardson et al. 2008). The purposes of the
\end{abstract}

utilizing different models (Dalzell et al. 2004; Jha et al. 2007). The usual intent of these examinations is to quantify the cumulative effects of changes in land use and management practices using a modeling approach.

The process of ranking alternative scenarios and determining an optimum CP for a particular condition should consider the dominant pollutant reduction processes and pollutant pathways from upland areas to stream segments. The process should also consider site-specific conditions, such as soils, topography, and land use. Several alternatives exist for selecting specific locations for implementation of CPs at a watershed scale. First, CPs can be randomly distributed throughout the watershed when specific information on dominant pollutant reduction processes and pathways is not available (random approach). Second, if a detailed understanding of watershed processes is already available, general guidelines on CP placement for specific conditions can be established without the benefit of a simulation model (conceptual approach). Third, modeling results can be used to target critical areas within the watershed where the implementation of CPs would be expected to yield the greatest benefit (modeling approach).

The random approach would require the least detailed watershed information, while the modeling approach would require the greatest detail. If little or no information is available for the watershed, a random approach can be used. Under this scenario, the CPs would be randomly located across the managed land in the watershed. At the intermediate level, the conceptual approach requires a basic understanding of the expected impacts of the CPs within a given watershed. The modeling approach requires the highest level of watershed data. Even though the modeling approach is advantageous because it can consider complex hydrologic and water quality processes in a watershed, it typically requires measured data for model

Jaepil Cho is a research associate for the USDA Agricultural Research Service (ARS) Northwest Watershed Research Center, Boise, Idaho. George Vellidis is a professor in the Department of Biological and Agricultural Engineering, University of Georgia, Tifton, Georgia. David D. Bosch is a research hydraulic engineer, Richard Lowrance is a research ecologist, and Timothy Strickland is a supervisory soil scientist for the USDA ARS Southeast Watershed Research Laboratory, Tifton, Georgia. 
calibration and validation. However, the modeling approach allows a watershed manager to decide where to locate CPs based upon a detailed understanding of dominant pollutant reduction processes and pollutant pathways from source areas to the stream.

A characteristic feature of many coastal plain watersheds is the presence of forested wetlands within the riparian zone. These areas form effective buffers of nonpoint source pollution (Vellidis et al. 2002, 2003; Gay et al. 2006) in this landscape because, in addition to surface runoff moving through the riparian zone, shallow groundwater is forced through the biologically active root zone of the forests by the underlying argillic horizons. In a long-term study, Vellidis et al. (2003) measured attenuation rates in excess of $65 \%$ for both total nitrogen (TN) and total phosphorus (TP).

In the Little River Experimental watershed (LREW) and similar coastal plain watersheds, riparian forests are increasingly being converted to wet pastures as farmers seek to increase field size in order to install large center pivot irrigation systems. Land within riparian zones is typically not converted into cropland because it is too wet for spring planting unless drained. In the LREW, no landowners receive conservation rental payments for maintaining riparian forest buffers.

In this paper, we examine the impacts of installing CPs within upland fields as well as the impacts of riparian buffers within the LREW. The specific objectives of this study are (1) to use mathematical simulation tools to assess the relative water quality effect of suites of CPs, (2) to compare three approaches for targeting the location of CPs, and (3) to evaluate the impact of riparian buffers within the watershed as a function of buffered area.

\section{Materials and Methods}

Little River Experimental Watershed. The $334 \mathrm{~km}^{2}\left(130 \mathrm{mi}^{2}\right)$ LREW, located near Tifton, Georgia, in the southeastern coastal plain of the United States (figure 1) is one of six regional experimental watersheds established by the USDA ARS as part of a national watershed hydrology research program begun in the 1950s. The LREW was established to provide research-quality hydrologic and natural resource data required to develop a better understanding of rainfall-streamflow relationships and to develop technologies required to resolve critical water resource and erosion

\section{Figure 1}

Map of the Little River Experimental watershed (LREW) showing the eight nested subwatersheds and the rain-gauge network. Watersheds are named by their outlets. For example, the outlet of the entire LREW is at B and so LREW is also known as LRB (Little River B). LRK is the subwatershed with its outlet at $\mathrm{K}$.

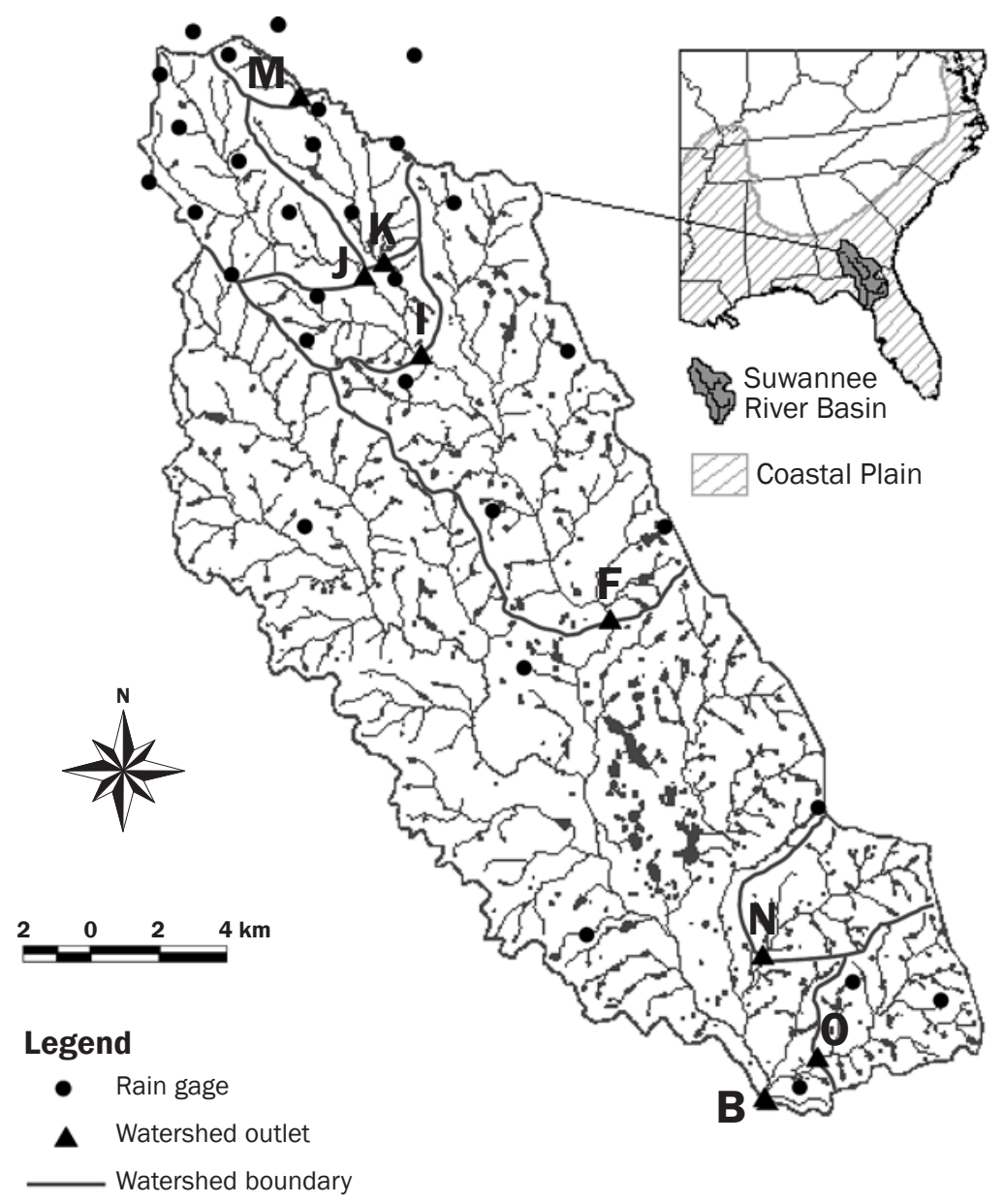

problems on agricultural watersheds within the southeastern coastal plain. Water quality records on the LREW began in 1974 and continue to the present day. Hydrologic, climatic, and water quality data for the LREW have been collected by the USDA ARS Southeast Watershed Research Laboratory in cooperation with the University of Georgia since 1968 (Bosch and Sheridan 2007; Bosch et al. 2007a, 2007b; Feyereisen et al. 2007a). Nine stream gauges and 31 rain gauges are currently active within the watershed.

The climate of the LREW is humid subtropical with a long growing season (Bosch et al. 2007b). Rainfall is unevenly distributed and often occurs as short-duration, highintensity convective thunderstorms (Bosch et al. 1999). The region has low topographic relief and is characterized by broad, flat alluvial floodplains, river terraces, and gently sloping uplands (Sheridan 1997).Approximately 36\% of the land has less than $2 \%$ slope, and only $7 \%$ of the land has slopes in excess of $5 \%$. Soils on the watershed are predominantly sands and sandy loams with initial infiltration rates in excess of $150 \mathrm{~mm} \mathrm{~h}^{-1}\left(6 \mathrm{in} \mathrm{hr}^{-1}\right)$ and one-hour infiltration rates of 30 to 100 $\mathrm{mm} \mathrm{h}^{-1}$ (1.1 to 3.9 in $\left.\mathrm{hr}^{-1}\right)$. Surface soils are underlain by the shallow and relatively impermeable argillic Hawthorne formation, which restricts downward movement of infiltrated water and leads to lateral movement towards the dense dendritic network of stream channels bordered by riparian forest wetlands (Sullivan et al. 2007). Riparian areas provide storage for storm runoff and lateral groundwater flow from adjacent upland areas and have great potential for buffering 
the impacts of runoff from agricultural areas (Lowrance et al. 1986, Lowrance et al. 1985). Deep percolation to the regional groundwater systems below the Hawthorne formation is minimal within the LREW (Sheridan 1997; Lowrance and Vellidis 1994).

The LREW is representative of a large area of mixed use, agricultural watersheds of the coastal plain ranging from Maryland to Texas. It is one of the largest intensively instrumented watersheds in the United States and is the only large-scale humid-region, low-gradient experimental watershed with continuous, long-term hydrologic and water quality data collection with nested study areas. Because of these unique characteristics, the LREW is the subject of two CEAP projects-one led by the USDA ARS Southeast Watershed Research Laboratory and the other led by the University of Georgia. In concert with the goals of CEAP, the broad objectives of both projects are to assess the long-term water quality effects of implemented CPs.

Little River Experimental Watershed Conservation Practices. Based upon analysis of LandSat images from 2003, 41\% of the LREW land area was in row crops and pasture at that time (Bosch et al.2006). Fortyseven different CPs have been implemented on the watershed with technical assistance by the USDA NRCS and/or through federal cost-share conservation programs. From 1980 to 2003, CPs had been implemented on approximately $11 \%$ of the land area in the LREW (Sullivan and Batten 2007). The practices with the greatest areal extent are nutrient management $(13.1 \%$ of the area in CPs), pest management (12.9\%), grassed waterways (9.6\%), contour farming $(9.5 \%)$, seasonal residue management $(8.9 \%)$, and terraces (8.8\%) (Sullivan and Batten 2007). Conservation practices may have also been applied to some of the remaining LREW cropped area by landowners without USDA NRCS assistance. However, we do not have records of these practices, and for the purposes of this study, we assume that no practices were implemented on this land area.

Hydrology and Water Quality Datasets. The hydrology, sediment, TN, and TP datasets for the watershed (Bosch et al. 2007a; Feyereisen et al. 2008) were used for model calibration and validation. Stream samples were taken on a weekly or more frequent basis and were analyzed for chloride, ammonium nitrogen, nitrate plus nitrite nitrogen,

\section{Figure 2}

The Soil and Water Assessment Tool (SWAT) hydrologic response units and the stream order with which they were affiliated for the riparian forest buffer stream order approach modeling scenario. The SWAT stream network is also shown.

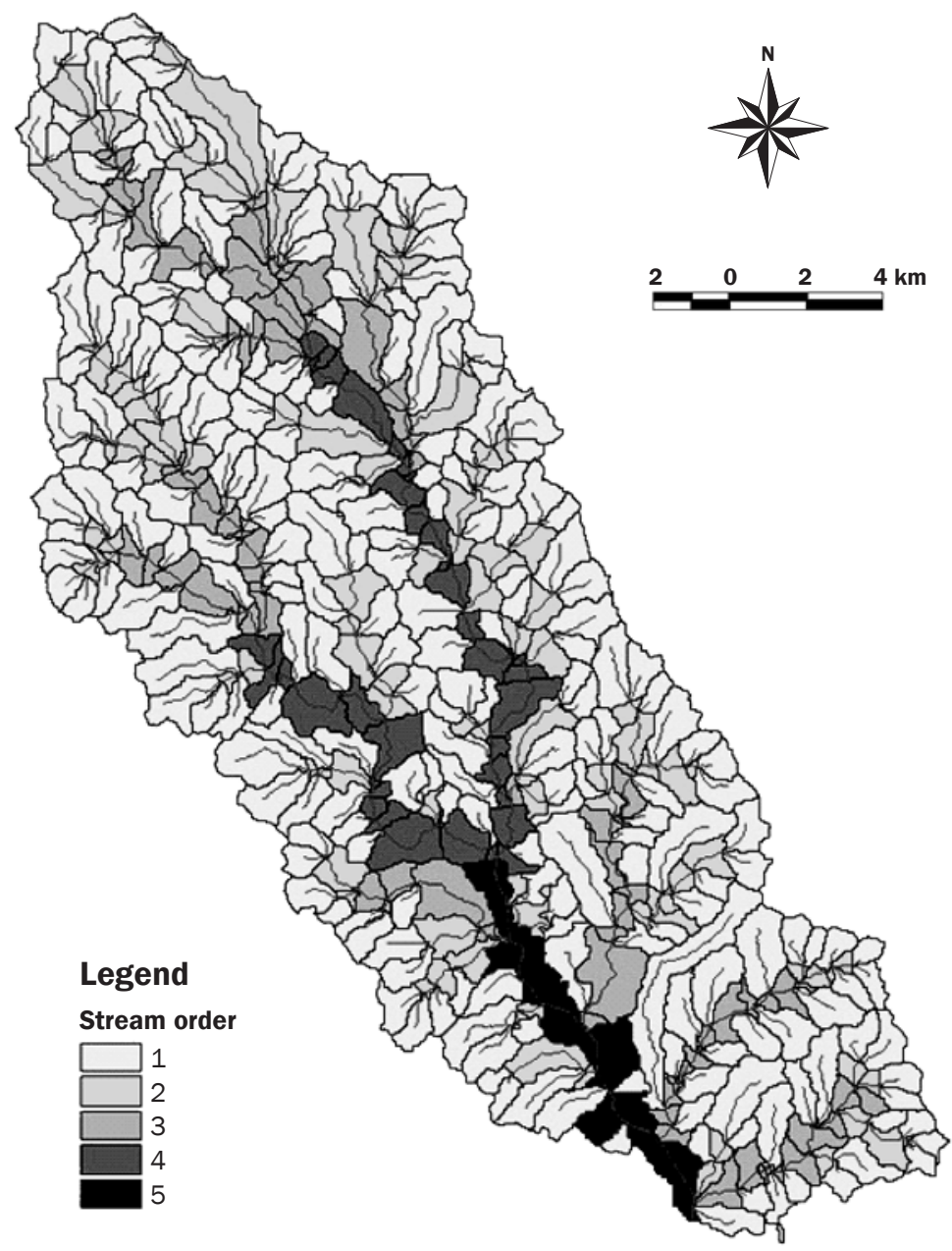

total Kjeldahl nitrogen, TP, and dissolved molybdate reactive phosphorus (Feyereisen et al. 2008). In addition to the sediment data that were published by Sheridan and Hubbard (1987) for 1974 to 1978 and 1979 to 1981 , and for 1984 to 1986 by Hubbard et al. (1990), another suspended sediment dataset is available for 2000 to present (Feyereisen et al. 2008). The TN and TP datasets contain daily estimates of concentration and streamflow loads derived from available watershed data, beginning in 1979 (Feyereisen et al. 2008). Details on the analytical methods are presented by Feyereisen et al. (2007b).

Soil and Water Assessment Tool Modeling. The Soil and Water Assessment Tool (SWAT) 2005 and the AVSWAT-X user interface were used for simulating water quality effects of alternative CP scenarios. AVSWAT-X (an extension of the ArcView geographic information system software) was used for creating model input using spatially distributed geographic coverages and weather data. The weather input, including maximum and minimum daily air temperature, solar radiation, and relative humidity data, were obtained from a University of Georgia weather station located $1 \mathrm{~km}(1.6 \mathrm{mi})$ eastnortheast of the watershed. Daily rainfall data from ten rain-gauge stations were used to consider spatial rainfall distribution (figure 1). A digital elevation model with a $30 \mathrm{~m}(100$ $\mathrm{ft}$ ) grid size was used to delineate subbasins, stream networks, and topographic parameters. Digital Soil Survey Geographic (SSURGO) database soil data (USDA NRCS Soil Data Mart) were used to derive the soil-related parameters. Agricultural field boundaries and nonrow cropland cover were obtained from the US Geological Survey 1993 ortho- 
Table 1

Parameters used for calibration and validation of the Soil and Water Assessment Tool model in Little River Experimental watershed (LREW).

\begin{tabular}{|c|c|c|c|c|c|}
\hline Parameters & Descriptions & Default & Range & Upper & $\begin{array}{l}\text { Calibrated } \\
\text { value }\end{array}$ \\
\hline ESCO.bsn & Soil evaporation compensation factor & 0.95 & 0 & 1 & 0.855 \\
\hline ADJ_PKR.bsn & $\begin{array}{l}\text { Peak rate adjustment factor for sediment routing in } \\
\text { the subbasin (tributary channels) }\end{array}$ & 1.0 & 0.5 & 2.0 & 1.75 \\
\hline PRF.bsn & Peak rate adjustment factor for sediment routing in the main channel & 1.0 & 0 & 2.0 & 0.75 \\
\hline SPCON.bsn & $\begin{array}{l}\text { Linear parameter for calculating the maximum amount of sediment } \\
\text { that can be re-entrained during channel sediment routing }\end{array}$ & 0.0001 & 0.0001 & 0.01 & 0.00089 \\
\hline PSP.bsn & Phosphorus availability index & 0.4 & 0.01 & 0.7 & 0.088 \\
\hline BIO_E.crop & $\begin{array}{l}\text { Radiation-use efficiency or biomass-energy ratio }\left(\left[\mathrm{kg} \mathrm{ha}^{-1}\right] /\left(\mathrm{MJ} \mathrm{m}^{-2}\right]\right) \\
\text { Corn } \\
\text { Cotton } \\
\text { Peanut }\end{array}$ & $\begin{array}{l}\text { Variable } \\
39 \\
15 \\
20\end{array}$ & 10 & 90 & $\begin{array}{l}39 \\
11 \\
17\end{array}$ \\
\hline EXT_COEF.crop & $\begin{array}{l}\text { Light extinction coefficient } \\
\text { Corn } \\
\text { Cotton } \\
\text { Peanut }\end{array}$ & $\begin{array}{r}\text { Variable } \\
0.65 \\
0.65 \\
0.65\end{array}$ & $\begin{array}{l}0 \\
0.4 \\
0.5 \\
0.6\end{array}$ & $\begin{array}{l}1 \\
0.65 \\
1.3 \\
0.8\end{array}$ & $\begin{array}{l}0.65 \\
0.6 \\
0.5 \\
0.6\end{array}$ \\
\hline CH_N(2).rte & Manning's " $n$ " value for the main channel & 0.014 & 0.01 & 0.3 & 0.015 \\
\hline GW_REVAP.gW & Rate of transfer from shallow aquifer to root zone & 0.02 & 0.02 & 0.2 & 0.046 \\
\hline GW_DELAY.gW & $\begin{array}{l}\text { Time required for water leaving the bottom of the root zone to } \\
\text { reach the shallow aquifer (days) }\end{array}$ & 31 & 0 & 500 & 0.036 \\
\hline GWQMN.gW & $\begin{array}{l}\text { Threshold water depth in shallow aquifer for return to } \\
\text { reach to occur }(\mathrm{mm})\end{array}$ & 0 & 0 & 5,000 & 66.7 \\
\hline HLIFE_NGW.gW & Half-life of nitrate in the shallow aquifer (days) & 365 & 0 & 365 & 3.7 \\
\hline CN2.mgt & $\begin{array}{l}\text { Curve number for crop areas-Non-crop } \\
\text { Crop } \\
\text { Non-crop }\end{array}$ & Variable & 35 & 98 & $\begin{array}{l}-15.3 \% * \\
-25.0 \% *\end{array}$ \\
\hline FILTERW.mgt & Width of edge-of-field filter strip (m) & 0 & 0 & 29 & 14 \\
\hline
\end{tabular}

* Percent reduction in curve number.

quadrangle aerial photographs with a $1 \mathrm{~m}$ $(3.3 \mathrm{ft})$ ground resolution. The spatial distribution of the field boundaries was assumed constant for both calibration and validation periods. Temporal changes in specific crops within the agricultural fields were considered by defining typical crop rotations based on harvested crop area data obtained from the USDA National Agricultural Statistics Service. University of Georgia Cooperative Extension recommendations were used for crop management options.

A nine-year simulation period from 1996 to 2004 was used to evaluate the water quality effects of the alternative CP scenarios. The model was calibrated with hydrology and water quality data from this period for subwatershed K (LRK) (figure 1), a key subwatershed within the LREW. Details of SWAT model parameterization for LREW were provided by Feyereisen et al. (2007b). For the validation, the parameter set from calibration on LRK was then used to simulate water quality effects for the entire LREW (LRB in figure 1) for the same period (1996 to 2004). The default SWAT in-stream processes were used for these simulations.

\section{Alternative Conservation Practice} Scenarios. The alternative CP scenarios we evaluated in this study focused on two components of the landscape: the portion of the LREW upland cropped areas that currently do not have documented CPs and the riparian buffer areas.

Upland Crop Production Area Scenarios. We applied two suites of CPs that we named crop management practices (CMP) and nutrient management practices (NMP) to the upland production area. The CMP suite consisted of four CPs (grassed waterways, terraces, contour farming, and conservation tillage) commonly used together in the LREW to control erosion, promote infiltration, and improve soil structure. The NMP suite consisted of whole-farm plans to reduce both nitrogen and phosphorus application rates by $30 \%$.

Three different scenarios for applying the CMP and NMP CPs to the upland crop production areas were evaluated. The three approaches consisted of randomly distributing the CPs (random approach), applying CPs as a function of stream order (stream order approach), and applying CPs to SWAT hydrologic response units (HRUs) as a function of nonpoint source pollution loads (modeling approach). The HRUs are areas (polygons) containing a unique combination of soil and land use. Pollutant loading from individual HRUs is reported by SWAT. The stream order approach was selected to represent the conceptual approach because of an anticipated relationship between proximity of the CP to the watershed outlet and subsequent water quality impact at the outlet. Under all three scenarios, the upland crop area to which CPs were applied increased incrementally from $11 \%$ of the watershed (baseline or current condition for documented CPs) to $41 \%$ of the watershed (complete implementation).

Using the random approach, SWAT divides watersheds (subbasins) into HRUs. Under the random approach scenario, CPs were applied to randomly selected groupings of HRUs. The HRUs were grouped to reduce the number of simulation runs needed to evaluate the scenario. The HRU groupings were sequentially aggregated as follows: $0 \%$ (baseline), 17\%, 33\%, 50\%, 67\%, $83 \%$, and $100 \%$ of the land not currently in 


\section{Figure 3}

Observed and simulated monthly (a) streamflow, (b) sediment, (c) total nitrogen (TN), and (d) total phosphorus (TP) at the outlet of subwatershed K (LRK).

(a)

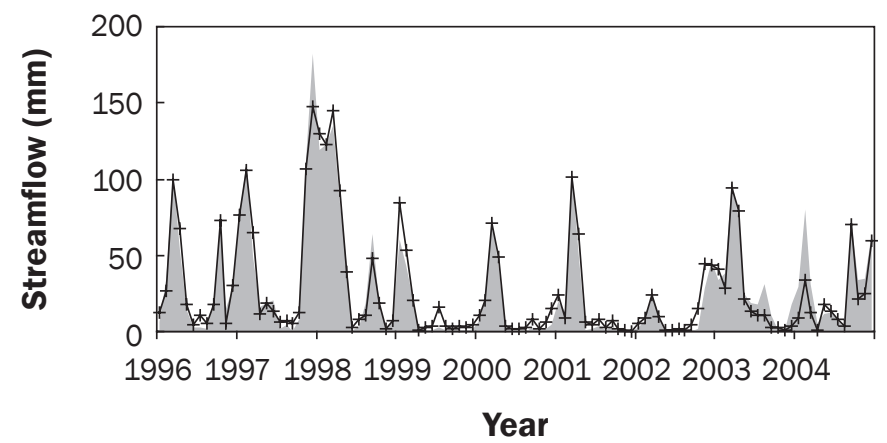

(b)

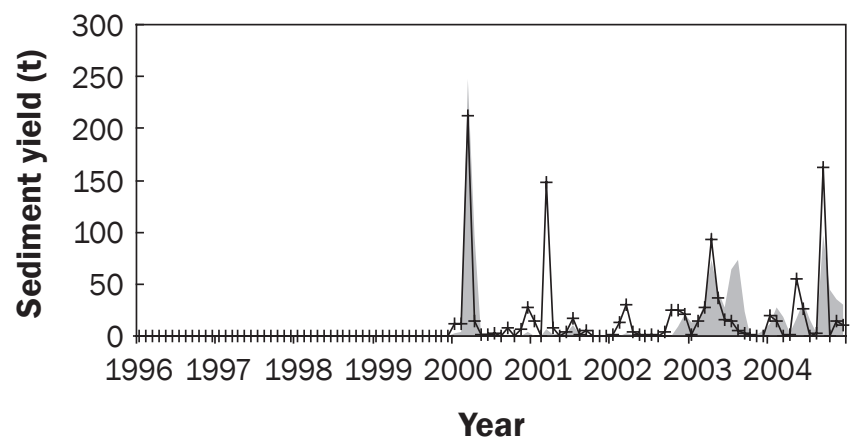

(d)

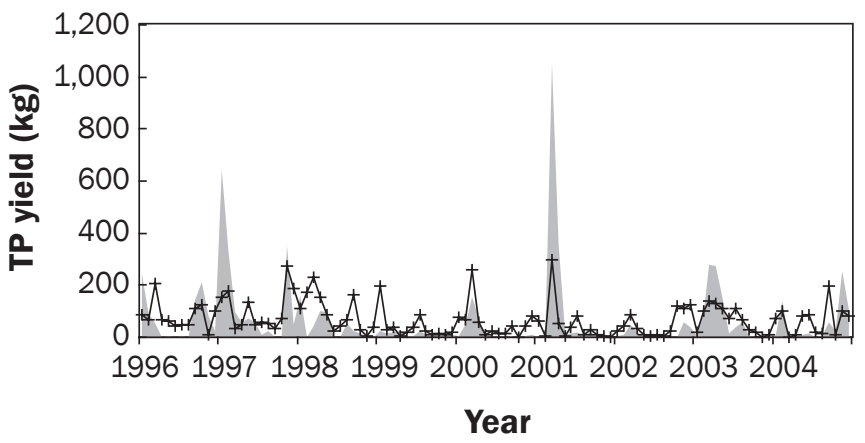

\section{Legend}

Observed

+ Simulated

documented CPs. Pollutant loadings (sediment, TN, TP) were compared for each of these increments.

Under the stream order approach scenario, CPs were applied as a function of stream order. The HRUs within subbasins with 1st order streams were aggregated, and CPs were applied to them. This consisted of $72 \%$ of the upland crop area currently without documented CPs. CPs were then applied to HRUs within subbasins with 2nd order streams (15\% of upland crop area), 3rd order streams ( $8 \%$ of upland crop area), 4 th order streams ( $4 \%$ of upland crop area), and finally 5 th order streams. Little River at the LREW outlet is a 5 th order stream (figure 2). Pollutant loadings were reported and compared for each of these increments.

Under the modeling approach scenario, HRUs were ranked by pollutant load from simulations representing the current or baseline condition. Different rankings were developed for sediment, TN, and TP. Conservation practices were then added to HRUs sequentially, with the CPs applied first to HRUs with the largest pollutant loads for each of the pollutants. As with the random approach, the HRUs were grouped into seven increments to reduce the number of simulation runs. The HRU groupings were sequentially aggregated as follows: $0 \%$ (baseline), $17 \%, 33 \%, 50 \%, 67 \%, 83 \%$, and $100 \%$ of the land not currently in CPs. Pollutant loadings were reported for each of these increments.

Riparian Buffer Scenarios. We evaluated the water quality effect of three riparian forest scenarios: current conditions $88 \%$ of all streams within the LREW with forested riparian zones), $0 \%$ riparian forest cover, and $100 \%$ riparian forest cover. We compared nonpoint source pollutant loads from HRUs under each of these scenarios.
The SWAT model does not currently contain an explicit method to represent riparian buffer zones. Instead, we used SWAT's FILTERW parameter to represent this landscape feature (table 1). Previous research on the watershed by Sheridan et al. (1999) showed that measured total reductions in sediment loads across the riparian forest buffers varied from $68 \%$ to $95 \%$, depending on management practices such as clear-cut, selectively thinned, and mature forest. For this analysis, a target reduction of $80 \%$ was selected. To achieve this within SWAT, we selected a $14 \mathrm{~m}$ (46 ft) filter strip width, which produces an $80 \%$ trapping efficiency (Neitsch et al. 2005; Cho et al. 2010). To represent the current conditions, the actual width of the riparian buffer along each stream section was assumed to vary from 0 to $14 \mathrm{~m}$. To determine the exact buffer width, land cover within a $14 \mathrm{~m}$ width surrounding 


\section{Figure 4}

Observed and simulated monthly (a) streamflow, (b) sediment, (c) total nitrogen (TN), and (d) total phosphorus (TP) at the Little River Experimental watershed outlet (LRB).

(a)

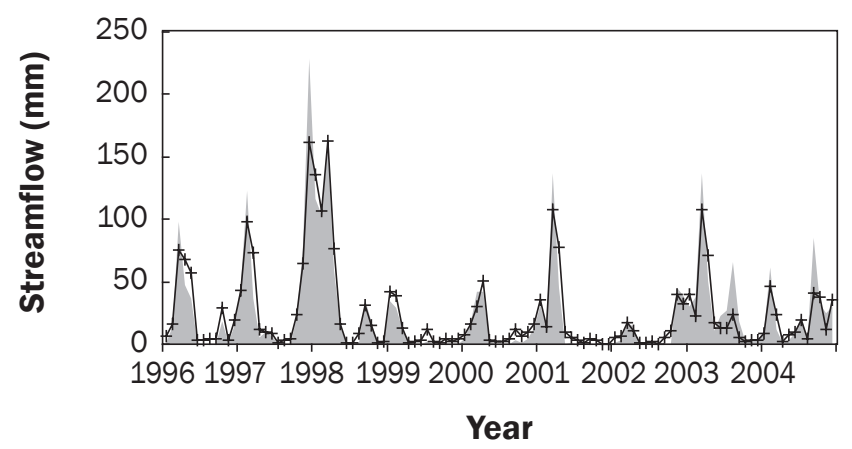

(c)

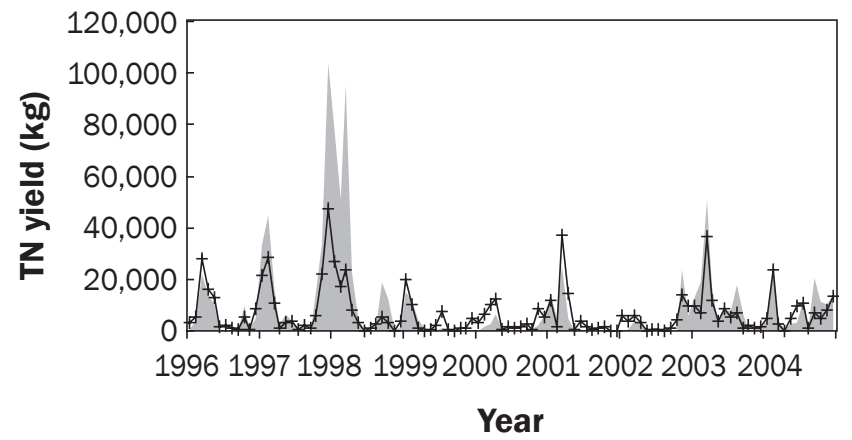

(b)

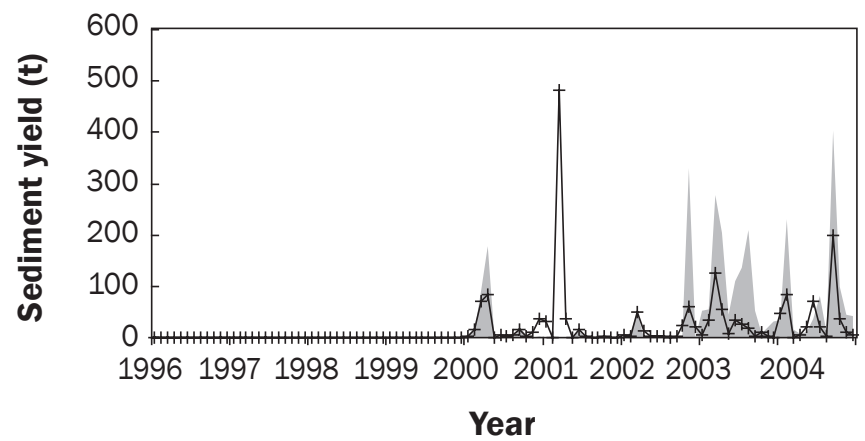

(d)

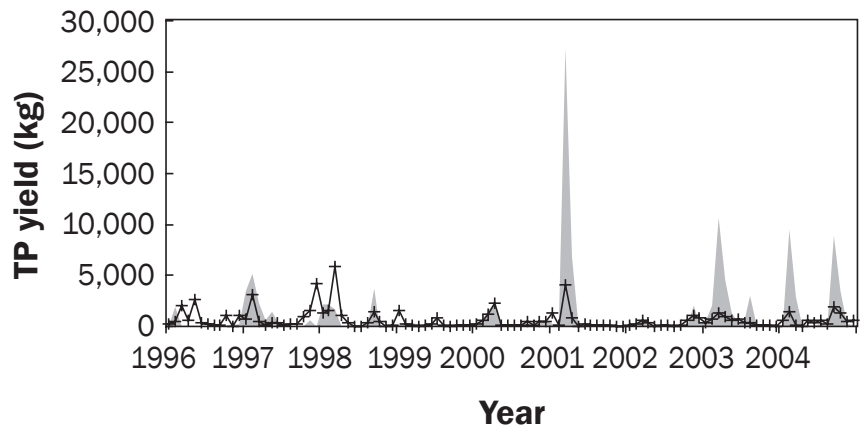

\section{Legend}

- Observed

+ Simulated

each simulated stream section was examined. Data from geographic information system land-use maps were used to represent the current conditions. Segments of the buffer that were forested for the entire $14 \mathrm{~m}$ width were assumed to be completely buffered. Segments without any forest cover were assumed to be nonbuffered. For segments of the buffer that contained both forest and other land uses, we determined the fraction of forest cover. The fraction was calculated as the forested area of the segment divided by the total area of the segment. This fraction, which varied between 0 to 1 , was then used to calculate the corresponding filter strip width in SWAT.

For the $100 \%$ scenario, all stream sections were assumed to be buffered by $14 \mathrm{~m}$ (46 ft) filter widths. For the $0 \%$ scenario, all HRUs were assigned a $0 \mathrm{~m}$ FILTERW. Pollutant loadings (sediment, TN, TP) were reported for each of these scenarios. The analyses were repeated using the stream order approach described earlier.

\section{Results and Discussion}

Calibration and Validation. A comparison between observed and simulated monthly streamflow, sediment yield, and TN and TP load for subwatershed LRK is presented in figure 3.Validation results for LRB, the outlet of the LREW, are presented in figure 4. Gaps in the observed data record indicate missing data. Mean annual calibration results for subwatershed LRK and validation results for LRB are presented in table 2. Percent error for streamflow, sediment yield, and TN and TP loadings at the LRK outlet were $0 \%, 1.5 \%, 9.0 \%$, and $8.6 \%$, respectively, all of which are well within the commonly accepted range of calibration error. Validation results for LRB had errors ranging from $7.8 \%$ for streamflow to $-42 \%$ for TP. The annual Nash-Sutcliffe Efficiency Index for LRB ranged from slightly below 0.5 for sediment and TP to 0.98 for streamflow (table 2). Taking into account that the goal of this study was to compare the relative differences in pollutant reduction rates and that the trend between the simulated and observed data were reasonable (figure 4), the validation results were considered acceptable.

Hydrologic Response Units and Watershed Loads. Implementation of the suite of CMPs on all the LREW upland cropped area without documented CPs (30\% of the LREW) resulted in HRU load reductions of $54.7 \%$ for sediment, $0.6 \%$ for TN, and $55.9 \%$ for TP at LRB, when compared to current or baseline conditions (figure 5). The bars in figure 5 represent the cumulative load of the HRU outlets and the load at the LREW outlet (LRB). The CPs included in the suite 
Table 2

Calibration results at the outlet of subwatershed K (LRK) and validation results at the outlet of the Little River Experimental watershed (LRB).

\begin{tabular}{|c|c|c|c|c|c|c|c|c|}
\hline \multirow{2}{*}{$\begin{array}{l}\text { Performance } \\
\text { measures }\end{array}$} & \multicolumn{2}{|c|}{ Streamflow $\left(\mathrm{mm} \mathrm{y}^{-1}\right)$} & \multicolumn{2}{|c|}{ Sediment $\left(t y^{-1}\right)$} & \multicolumn{2}{|c|}{$\mathrm{TN}\left(\mathrm{kg} \mathrm{y}^{-1}\right)$} & \multicolumn{2}{|c|}{ TP $\left(\mathrm{kg} \mathrm{y}^{-1}\right)$} \\
\hline & LRK & LRB & LRK & LRB & LRK & LRB & LRK & LRB \\
\hline Observed & 326 & 284 & 225 & 589 & 5,615 & 111,237 & 746 & 13,393 \\
\hline Percent error & 0.0 & 7.8 & 1.5 & -37.8 & 9.0 & -25.7 & 8.6 & -42.0 \\
\hline Daily NSE & 0.77 & & & & & & & \\
\hline
\end{tabular}

Notes: TN = total nitrogen. TP = total phosphorus. NSE = Nash-Sutcliffe Efficiency Index.

* Using the default Soil and Water Assessment Tool in-stream processes.

of CMPs primarily control pollutants associated with erosion and do little to attenuate dissolved nitrogen, the primary component in simulated TN. In the LREW landscape, dissolved nitrogen generally moves laterally in shallow groundwater, which is eventually discharged to streams.

The suite of NMPs resulted in minimal HRU reductions of sediment loads $(0.8 \%)$, small reductions of TP loads (4.3\%) and moderate reductions of TN loads (10.3\%) (figure
5). An uninterrupted $14 \mathrm{~m}$ (46 ft) riparian forest buffer resulted in a $20.5 \%$ HRU reduction in sediment loads, $7 \%$ reduction of TN loads, and a $19.5 \%$ reduction of TP loads. Based on modeling results, the CMPs are the most effective at reducing sediment and TP loads. However, riparian forest buffers appear to provide the most comprehensive load reduction as they can effectively reduce loads of all three pollutants.
Load Reduction Rates from Upland Crop Production Areas. Figure 6 presents the loading reduction rates resulting from each of the three modeling scenarios evaluated (random approach, stream order approach, and modeling approach) by applying CMPs to the upland crop production areas. Rates were calculated based on cumulative loads delivered to HRU outlets. The data points in figure 6 represent load reductions resulting from the sequentially aggregating CPs within

\section{Figure 5}

Simulated total pollutant load from the hydrologic response units and at the Little River Experimental watershed outlet for the current cropping practices (current CP), following implementation of the suite of crop management practices (maximum CMP), following implementation of the suite of nutrient management practices (maximum NMP), and following implementation of $14 \mathrm{~m}$ riparian buffers along all stream sections (14 $\mathrm{m}$ FILTERW) for sediment, total nitrogen, and total phosphorus.
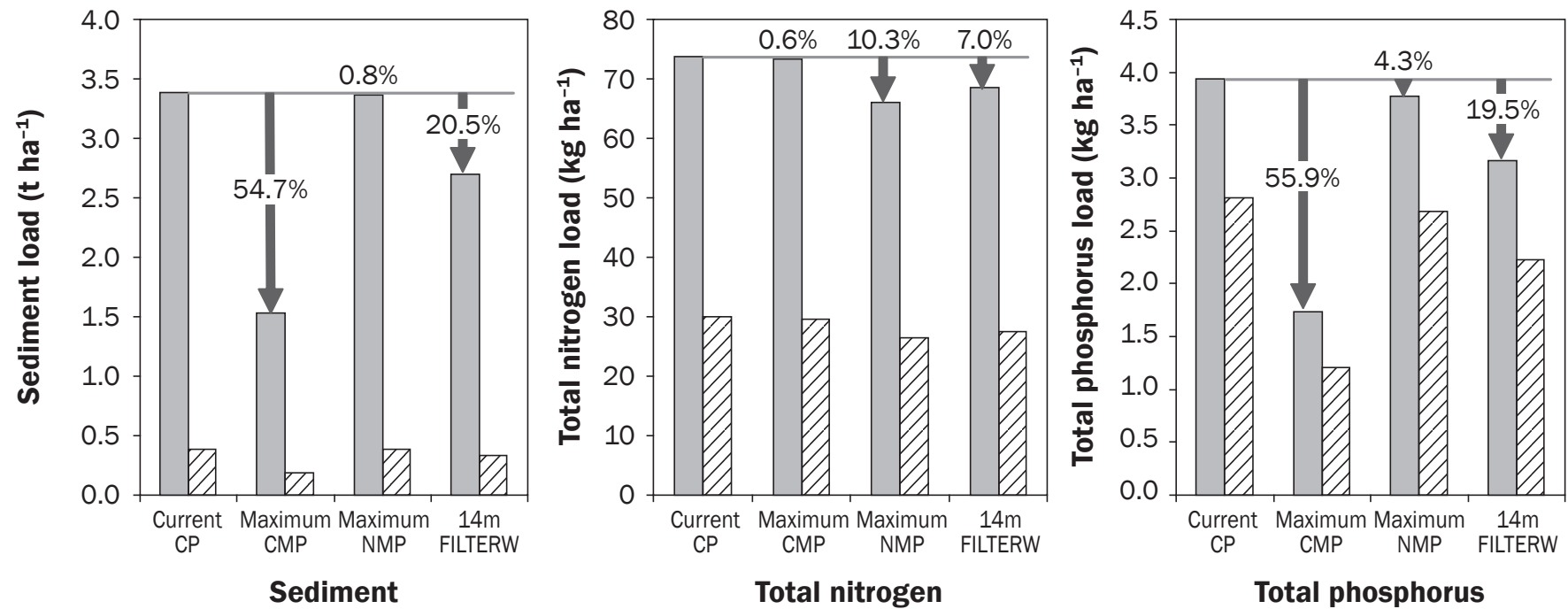

Legend

$\square$ HRU outlet load DIPT LREW outlet load

Notes: HRU = hydrologic response unit. LREW = Little River Experimental watershed. 


\section{Figure 6}

Load reduction rates resulting from each of the three modeling scenarios evaluated (random approach, stream order approach, and modeling approach) by applying crop management practices to the upland crop production areas. Rates were calculated based on loads delivered to hydrologic response unit outlets.
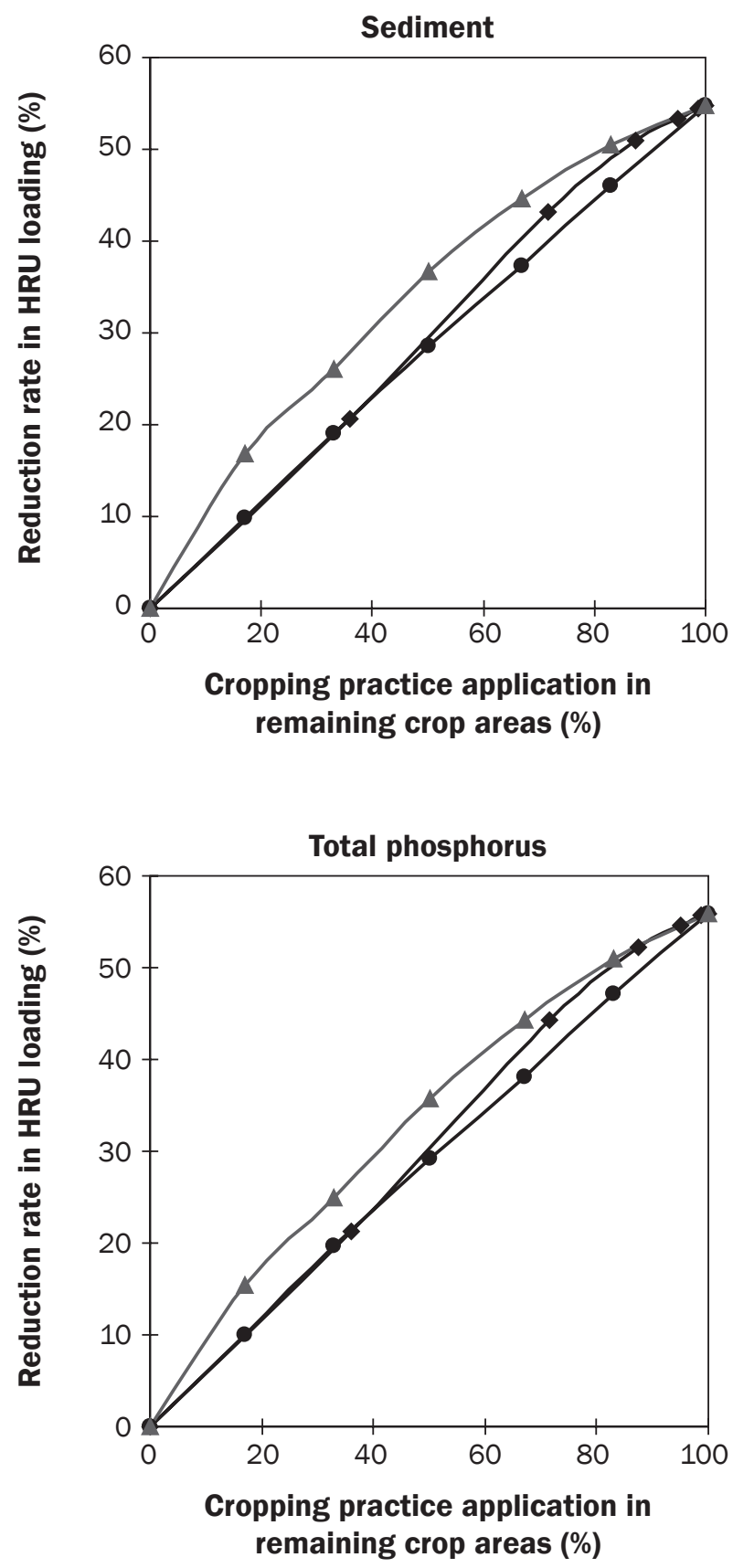

Legend

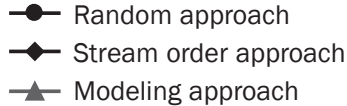

Note: $\mathrm{HRU}=$ hydrologic response unit.

HRUs as described previously. While all three scenarios ultimately resulted in the same reduction in loading at $100 \%$ implementation, the modeling approach (prioritizing implementation based on HRU baseline pollutant loads) was clearly the most efficient approach for targeting implementation of additional CMPs. For both sediment and TP, the greatest rate of reduction was achieved when implementing CPs on the highest priority $20 \%$ of the LREW upland cropped area without currently documented CPs. Results are not presented for TN because the reduction rates resulting from the selected suite of CMPs was minimal.

Figure 7 presents TN and TP loading reduction rates resulting from the three NMP modeling scenarios. Rates were calculated based on loads delivered to HRU outlets. Although the modeling approach is again the most efficient method for targeting implementation of CPs, the reduction rates for NMP were much lower than those estimated for application of CMP.

Load Reduction from Riparian Forest Buffers. Figure 8 presents the results of the three riparian buffer modeling scenarios$0 \%$, current conditions (88\%), and 100\%. The simulation results indicate that the current extent of riparian forest buffer accounts for a $75 \%$ reduction in sediment load at the watershed outlet of LRB, when compared to a hypothetical $0 \%$ riparian forest cover (figure 8). An additional 21\% reduction (80\% total reduction) in sediment loads can be expected by increasing riparian forest cover from $88 \%$ to $100 \%$. Total phosphorus reduction mirrors that of sediment. The current condition results in 32\% lower TN loads than $0 \%$ riparian forest cover, while 100\% riparian forest cover results in an additional $7 \%$ reduction (37\% total reduction). A long-term fieldscale study conducted within the LREW by Vellidis et al. (2003) reported a 66\% reduction in TP loads and a 59\% reduction of TN loads by a riparian forest adjacent to a heavily loaded liquid dairy manure land application field. Given that SWAT does not explicitly simulate riparian forest buffers, the simulated results appear reasonable. All together these results illustrate the important water quality function of riparian forests in the coastal plain landscape. Because these are primarily natural buffers and not buffers installed through various $\mathrm{CPs}$, significant loads of sediment and nutrients are removed by these buffers at no cost to the American taxpayer. 
Figure 9 presents the results of the stream order approach scenario analysis as applied to riparian forest buffers. The largest HRU load reductions were achieved by restoring riparian forest buffers along 1st and 2nd order streams-21.6\% and $21.7 \%$ reduction, respectively. This is a logical result both because 1 st and 2nd order streams are in closest proximity to upland agricultural production sites (large stream orders tend to have extended flood plains in the LREW landscape) and because the greatest loss of riparian forest has occurred along 1st and 2nd order streams for the reasons discussed earlier. Other recently published research supports these findings (Ekness and Randhir 2007; Tomer et al. 2009). Table 3 presents the percent of stream length with intact riparian forests as a function of stream order. Streams of 3rd order or higher have intact riparian forest buffers on more than $95 \%$ of their length.

\section{Summary and Conclusions}

Mathematical simulation tools (models) that allow the user to compare the relative water quality effect of various management scenarios are valuable for identifying management strategies for achieving desired water quality goals. This study indicates that implementing CPs in subwatersheds with the largest nonpoint source pollution loads will likely result in the most rapid water quality improvements. Furthermore, this prioritization scheme results in the most rapid (nonlinear) water quality improvements. The other implementation schemes resulted in linear water quality improvement. Because few watersheds have sufficient monitoring data with which to prioritize subwatersheds, models provide a reasonable and perhaps more economical alternative for conservation planners. The

\section{Table 3}

Riparian forest cover as a function of stream order under current conditions.

\begin{tabular}{|c|c|}
\hline Stream order & $\begin{array}{l}\text { Percent of stream } \\
\text { with intact RFB }\end{array}$ \\
\hline 1 & 83.4 \\
\hline 2 & 88.9 \\
\hline 3 & 96.6 \\
\hline 4 & 99.3 \\
\hline 6 & 99.7 \\
\hline Total LREW & 88.3 \\
\hline
\end{tabular}

\section{Figure 7}

Load reduction rates resulting from each of the three modeling scenarios evaluated (random approach, stream order approach, and modeling approach) by applying nutrient management practices to the upland crop production areas. Rates were calculated based on loads delivered to hydrologic response unit outlets.
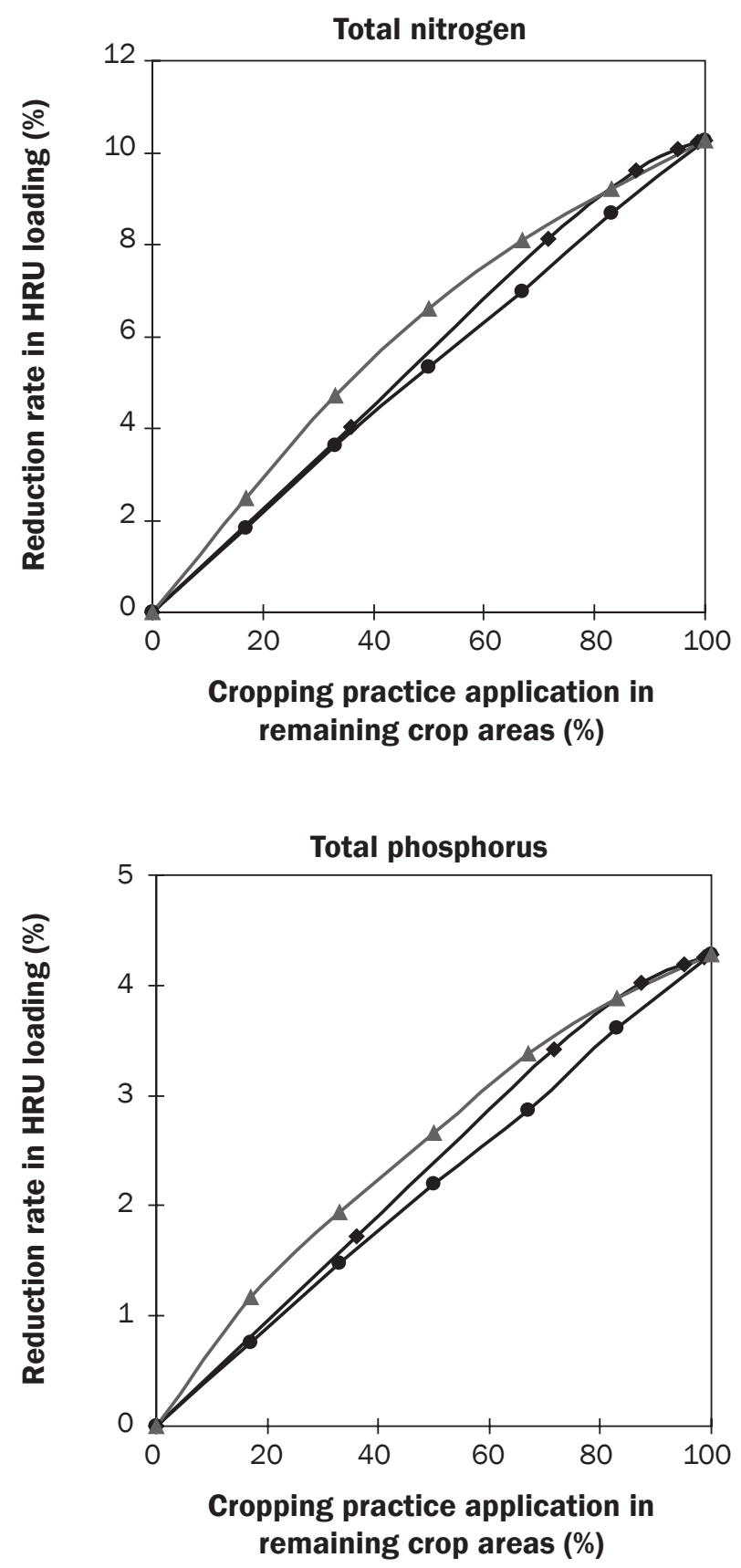

Legend

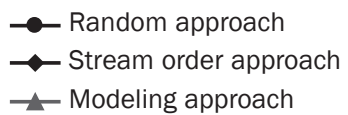

Note: HRU = hydrologic response unit. 


\section{Figure 8}

Simulated pollutant loads at Little River Experimental watershed outlet (LRB) for the three riparian buffer scenarios- $0 \%$ riparian forest cover, current conditions (88\%), and $100 \%$ riparian forest cover. The arrows indicate the simulated percent reduction from the $0 \%$ riparian forest cover condition or the simulated reduction between the current condition and $100 \%$ riparian forest cover.

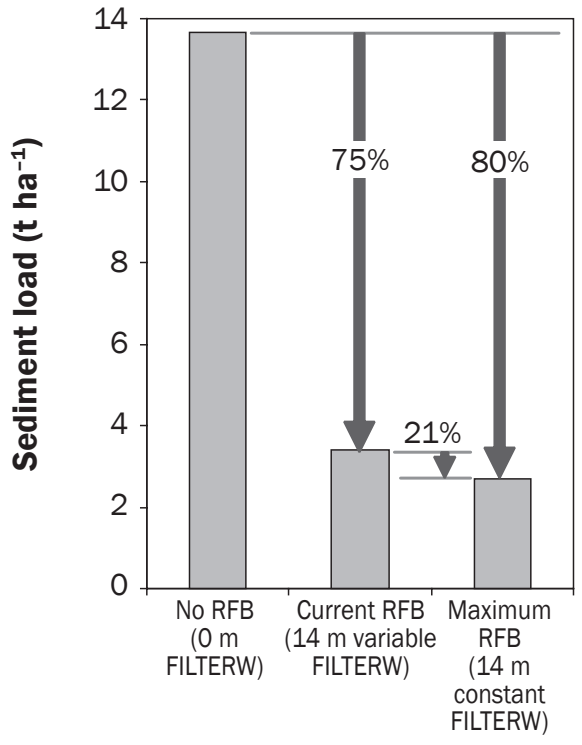

Sediment

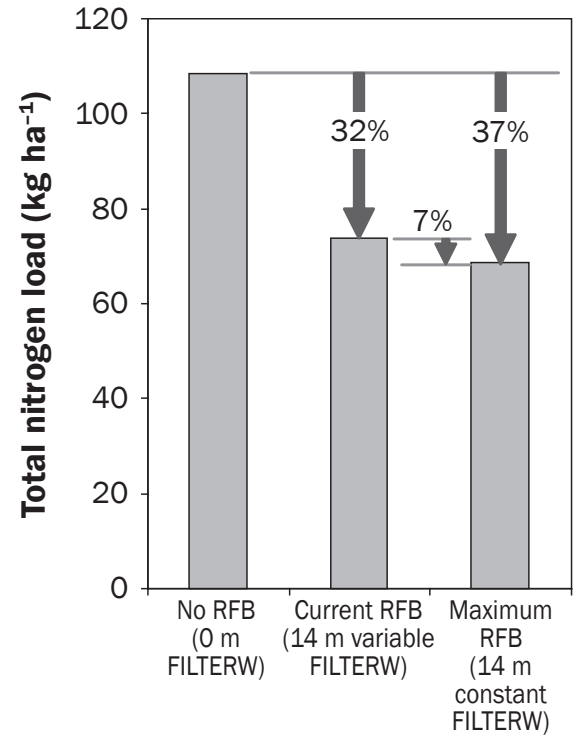

Total nitrogen

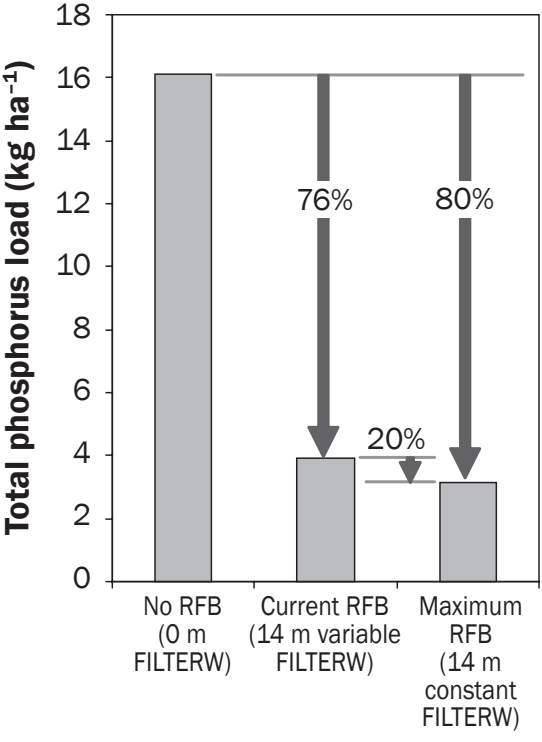

Total phosphorus

Notes: RFB = riparian forest buffer. FILTERW = filter width

\section{Figure 9}

Load reduction rates resulting from the stream order approach scenario analysis as applied to riparian forest buffers.

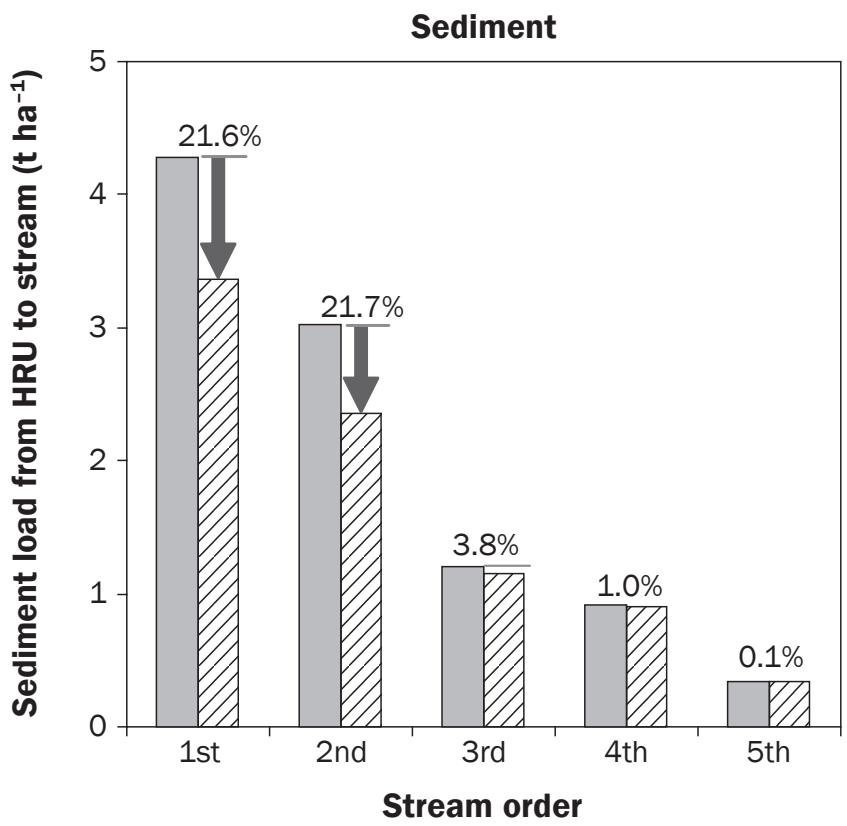

Legend

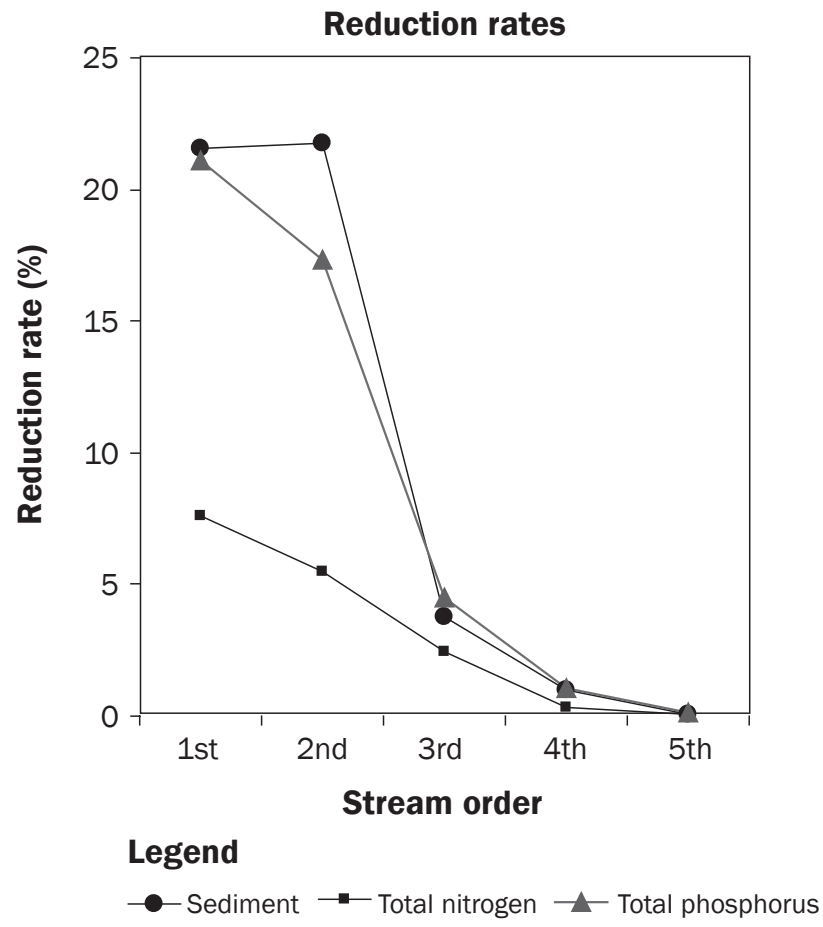

Note: $\mathrm{HRU}=$ hydrologic response unit. $\mathrm{RFB}=$ riparian forest buffer. 
greatest water quality returns for the investment are obtained when the suite of CMPs or the suite of NMPs are implemented on the $50 \%$ of the cropland with the greatest nonpoint source pollution loads.

The CMPs, the suite of practices targeting erosion consisting of grassed waterways, terraces, contour farming, and conservation tillage, all of which are very popular in the LREW, results in the greatest reductions of sediment and TP from upland crop areas. The NMPs, the suite of whole-farm practices targeting nutrient reduction, results in the greatest $\mathrm{TN}$ reductions. However, much greater reductions were achieved with CMPs than with NMPs. Overall, riparian forest buffers offer the most comprehensive reduction of nonpoint source pollutant loads. Simulation results indicate that the current level of riparian forest cover in the LREW may be the single greatest contributor to nonpoint source pollutant reduction.

\section{Acknowledgements}

Funding for this project was provided by a grant from the USDA Cooperative State Research, Education, and Extension Service Integrated Research, Education, and Extension Competitive Grants Program-National Integrated Water Quality Program, CEAP (Award No. 2005-5113002377), by USDA ARS Current Research Information System project funds, and by Hatch and State funds allocated to the Georgia Agricultural Experiment Stations.

\section{References}

Bosch, D.D., and J.M. Sheridan. 2007. Stream discharge database, Little River Experimental watershed, Georgia, United States. Water Resources Research 43(9):W09473, doi:10.1029/2006WR005833.

Bosch, D.D., J.M. Sheridan, R.R. Lowrance, R.K Hubbard, T.C. Strickland, G.W. Feyereisen, and D.G. Sullivan. 2007a. Little River Experimental watershed database. Water Resources Research 43:W09470, doi:10.1029/2006WR005844.

Bosch, D.D., J.M. Sheridan, and L.K. Marshall. 2007b. Precipitation, soil moisture, and climate database, Little River Experimental watershed, Georgia, United States. Water Resources Research 43:W09472, doi:10.1029/2006WR005834.

Bosch, D.D., J.M. Sheridan, and D.G. Sullivan. 2006. Hydrologic impact of land-use changes in coastal plain watersheds. Transactions of American Society of Agricultural and Biological Engineers 49(2):423-432.

Bosch, D.D., J.M. Sheridan, and F.M. Davis. 1999. Rainfall characteristics and spatial correlation for the Georgia coastal plain. Transactions of American Society of Agricultural and Biological Engineers 42(6):1637-1644.

Cho, J., D. Bosch, R. Lowrance, T. Strickland, Y. Her, and G. Vellidis. 2010. Effect of watershed subdivision and filter width on SWAT simulation of a Coastal Plain watershed
Journal of the American Water Resources Association 46(3):586-602, doi:10.1111/j.1752-1688.2010.00436.x.

Dalzell, B.J., P.H. Gowda, and D.J. Mulla. 2004. Modeling sediment and phosphorus losses in an agricultural watershed to meet TMDLs. Journal of the American Water Resources Association 40(2):533-543.

Dillaha, T.A. 1990. Role of best management practices in restoring the health of the Chesapeake Bay. In Perspectives on the Chesapeake Bay, 1990: Advance in Estuarine Sciences. Chesapeake Bay Program, CBP/TRS41/90. Washington DC: US Environmental Protection Agency.

Duriancik, L.F., D. Bucks, J.P. Dobrowolski, T. Drewes, S.D. Eckles, L. Jolley, R.L. Kellog, D. Lund, J.R Makuch, M.P. O’Neill, C.A. Rewa, M.R. Walbridge, R. Parry, and M.A. Weltz. 2008. The first five years of the Conservation Effects Assessment Project. Journal of Soil and Water Conservation 63(6):185a-188a, doi:10.2489/jswc.63.6.185A

Ekness, P., and T. Randhir. 2007. Effects of riparian areas, stream order, and land use disturbance on watershedscale habitat potential: An ecohydrologic approach to policy. Journal of the American Water Resources Association 43(6):1468-1482.

Feyereisen, G.W., R. Lowrance, T.C. Strickland, D.D. Bosch, and J.M. Sheridan. 2008. Long-term stream chemistry trends in the southern Georgia Little River Experimental watershed. Journal of Soil and Water Conservation 63(6):475-486, doi:10.2489/jswc.63.6.475.

Feyereisen, G.W., R. Lowrance, T.C. Strickland, J.M Sheridan, R.K. Hubbard, and D.D. Bosch. 2007a. Long-term water chemistry database, Little River Experimental watershed, southeast Coastal Plain, United States. Water Resources Research 43(9):W09474, doi:10.1029/2006WR005835.

Feyereisen, G.W., T.C. Strickland, D.D. Bosch, and D.G Sullivan. 2007b. Evaluation of SWAT manual calibration and input parameter sensitivity in the Little River watershed. Transactions of American Society of Agricultural and Biological Engineers 50(3):843-855.

Gay, P., G. Vellidis, and J.J. Delfino. 2006. The attenuation of atrazine and its major degradation products in a restored riparian buffer. Transactions of American Society of Agricultural and Biological Engineers 49(5):1323-1339.

Hubbard, R.K., J.M. Sheridan, and L.R. Marti. 1990 Dissolved and suspended-solids transport from coastalplain watersheds. Journal of Environmental Quality 19(3):413-420.

Jha, M.K., P.W. Gassman, and J.G.Arnold. 2007. Water quality modeling for the Raccoon River watershed using SWAT. Transactions of American Society of Agricultural and Biological Engineers 50(2):479-493.

Lowrance, R., J.K. Sharpe, and J.M. Sheridan. 1986. Longterm sediment deposition in the riparian zone of a coastal-plain watershed. Journal of Soil and Water Conservation 41(4):266-271.

Lowrance, R., and G. Vellidis. 1994. A conceptual model for assessing ecological risk to water quality function of bottomland hardwood forests. Environmental Management 19(2):239-258.
Lowrance, R.R., R.A. Leonard. L.E. Asmussen, and R.L. Todd. 1985. Nutrient budgets for agricultural watersheds in the southeastern coastal-plain. Ecology 66(1):287-296.

Neitsch, S.L., J.G. Arnold, J.R. Kiniry, and J.R. Williams. 2005. Soil and Water Assessment Tool theoretical documentation, version 2005.

Richardson, C.W., D.A. Bucks, and E.J. Sadler. 2008. The Conservation Effects Assessment Project benchmark watersheds: Synthesis of preliminary findings. Journal of Soil and Water Conservation 63(6):590-604 doi:10.2489/jswc.63.6.590.

Sheridan, J.M. 1997. Rainfall-streamflow relations for coastal plain watersheds. Applied Engineering in Agriculture 13(3):333-344.

Sheridan, J.M., and R.K. Hubbard. 1987. Transport of solids in streamflow from Coastal-Plain watersheds. Journal of Environmental Quality 16(2):131-136.

Sheridan, J.M., R. Lowrance, and D.D. Bosch. 1999. Management effects on runoff and sediment transport in riparian forest buffers. Transactions of American Society of Agricultural and Biological Engineers 42(1):55-64.

Sullivan, D.G., and H.L. Batten. 2007. Little River Experimental watershed, Tifton, Georgia, United States: A historical geographic database of conservation practice implementation. Water Resources Research 43(9):W09475, doi:10.1029/2007WR006143.

Sullivan, D.G., H.L. Batten, D. Bosch, J. Sheridan, and T. Strickland. 2007. Little river experimental watershed, Tifton, Georgia, United States: A geographic database. Water Resources Research 43(9):W09471, doi:10.1029/2006WR005836

Tomer, M.D., M.G. Dosskey, M.R. Burkart, D.E. James, M.J. Helmers, and D.E. Eisenhauer. 2009. Methods to prioritize placement of riparian buffers for improved water quality. Agroforestry Systems 75:17-25.

Vellidis G., R. Lowrance, P. Gay, and R.K. Hubbard. 2003. Nutrient transport in a restored riparian wetland.Journal of Environmental Quality 32(2):711-726.

Vellidis, G., R. Lowrance, P. Gay, and R.D. Wauchope. 2002. Herbicide transport in a restored riparian forest buffer system. Transactions of American Society of Agricultural and Biological Engineers 45(1):89-97. 